\title{
PREPARATION OF SUBMICROSCALE Ag-COATED Cu PARTICLES BY MULTI-STEP ADDITION OF Ag PLATING SOLUTION AND ANTIOXIDATION PROPERTIES FOR DIFFERENT Ag SHELL THICKNESSES
}

\begin{abstract}
For application as a low-cost conductive filler material, submicroscale $\mathrm{Cu@Ag} \mathrm{particles} \mathrm{were} \mathrm{fabricated} \mathrm{at} \mathrm{room} \mathrm{temperature}$ without any reductants by a multi-step addition method using an ethylene glycol-based Ag plating solution. Scanning electron microscopy images of the Ag-coated Cu particles demonstrated the formation of discrete Ag particles less than $100 \mathrm{~nm}$ in size as well as a thin Ag coating on Cu particles, during the early addition steps. However, as the thickness of the Ag coating increased, the small Ag particles agglomerated into Ag coatings with an increase in the number of Ag plating steps. Owing to the absence of additives such as surfactants, a comparison between the microstructural images and calculations indicated increased agglomeration between fabricated Ag-coated $\mathrm{Cu}$ particles with an increase in the number of Ag plating steps. However, thermogravimetric-differential scanning calorimetry of the agglomerated Ag-coated $\mathrm{Cu}$ particles after the fifth addition of the Ag plating solution demonstrated their antioxidation behavior even after $70 \mathrm{~min}$ in air at $150^{\circ} \mathrm{C}$.
\end{abstract}

Keywords: Ag-coated Cu particle, Submicrometer, Glycol-based Ag plating solution, Mult-step addition, Antioxidation

\section{Introduction}

Because of advantages of paste materials such as the simplicity of the process for their mass production and their fast adhesion, the application of paste materials is increasing, and novel paste materials have been proposed for electronic packaging [1-10]. For example, Eom et al. prepared a hybrid paste containing both solder powder and $\mathrm{Cu}$ particles as a filler material for chip bonding and confirmed the processability and superior thermal conductivity of the cured paste [11]. To enhance both the processability and the electrical and thermal properties by suppressing the oxidation of pure $\mathrm{Cu}$ particles, Cu particles should be replaced with Ag-coated Cu (Cu@Ag) particles [12-17]. In addition, if tiny Cu@Ag particles can be added in the vacant spaces between microscale solder and $\mathrm{Cu@}$ Ag particles, the thermal and electrical conductivity of the cured paste can be enhanced with only a slight increase in the initial viscosity of the paste [18]. Thus, submicroscale Cu@Ag particles are anticipated to serve as an effective auxiliary filler material in conductive pastes.

To avoid the use of any additives, such as reductants or surfactants, submicroscale Cu@Ag particles with Ag contents exceeding $13 \mathrm{wt} \%$ were fabricated and characterized in this study. Because non-uniformity of the Ag coating and significant agglomeration between $\mathrm{Cu@Ag} \mathrm{particles} \mathrm{were} \mathrm{observed} \mathrm{in}$ preliminary experiments when the total amount of Ag precursor was injected at once, a multi-step addition method with a Ag plating solution was used. Then, the oxidation resistance of Cu@Ag particles heated in air was assessed as a function of the Ag shell thickness.

\section{Materials and methods}

The submicrometer-sized $\mathrm{Cu}$ particles that served as the core material in the Ag-coated $\mathrm{Cu}$ particles were synthesized in-house. The Ag plating solution for the fabrication of 3-wt\% Ag-coated $\mathrm{Cu}$ consisted of $0.884 \mathrm{M}$ of silver nitrate $\left(\mathrm{AgNO}_{3}\right.$, $\sim 99.5 \%$, Nanjing Chemical Reagent Co. Ltd) that was dissolved in $8 \mathrm{ml}$ of ethylene glycol. The solution was injected dropwise at a rate of $3.3 \mathrm{ml} / \mathrm{min}$ into $200 \mathrm{ml}$ of ethylene glycol containing $2 \mathrm{M}$ of Cu particles (EG, 99.7\%, SK Networks). During the plating, the mixture was continuously stirred at a rate of $300 \mathrm{rpm}$. The plating step was repeated five or eight times with an interval of $10 \mathrm{~min}$ after each step. After the completion of the reaction, centrifugation at $7000 \mathrm{rpm}$, decantation, and rinsing using methyl alcohol (99.5\%, Samchun Pure Chemicals Co.) were repeated three times. Finally, the Ag-coated $\mathrm{Cu}$ particles were gathered after drying in a vacuum chamber.

The size and surface morphology of the Ag-coated $\mathrm{Cu}$ particles were observed with back-scattered electron (BEI) images obtained with a scanning electron microscope (SEM, VEGA 3 LMU, TESCAN Ltd.). The Ag content in the Ag-coated Cu powder was measured using energy dispersive spectroscopy (EDS,

\footnotetext{
* DEPARTMENT OF MATERIALS SCIENCE \& ENGINEERING, SEOUL NATIONAL UNIVERSITY OF SCIENCE \& TECHNOLOGY, SEOUL 139-743, REPUBLIC OF KOREA

* Corresponding author: pljh@seoultech.ac.kr
} 


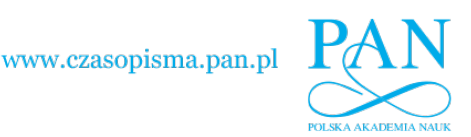

1138

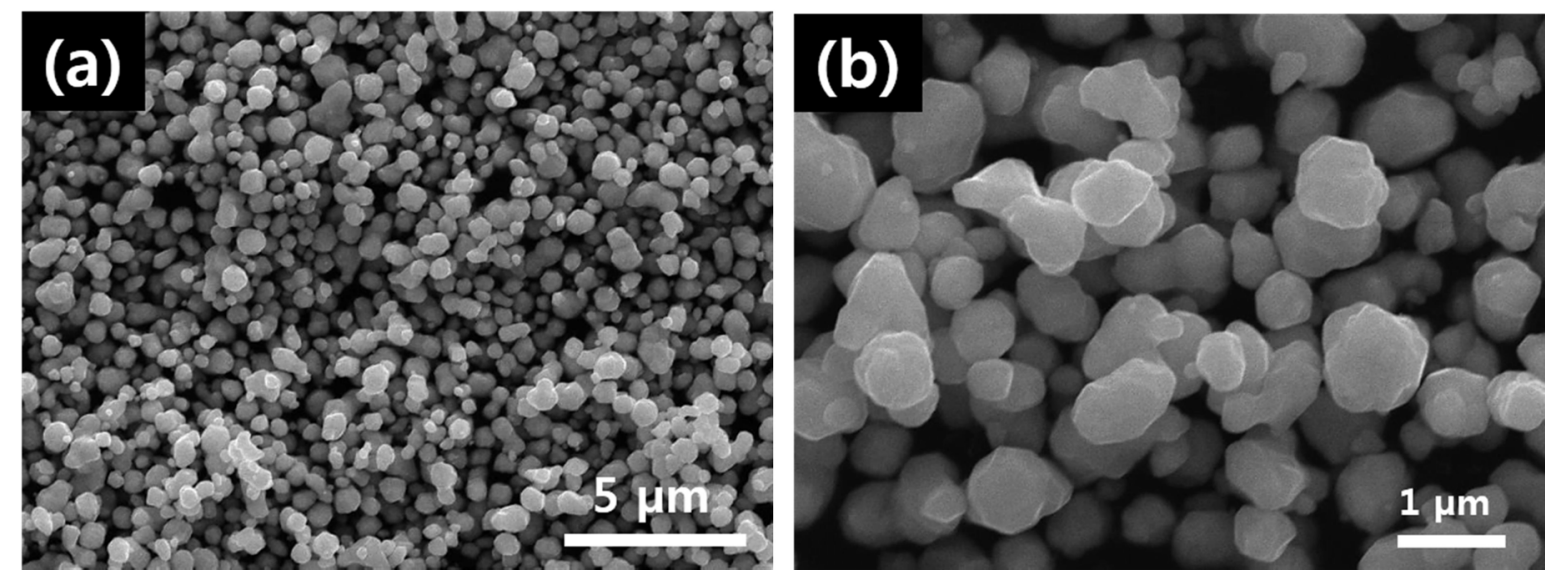

Fig. 1. (a) Low- and (b) high-magnification SEM image of submicroscale-core Cu particles
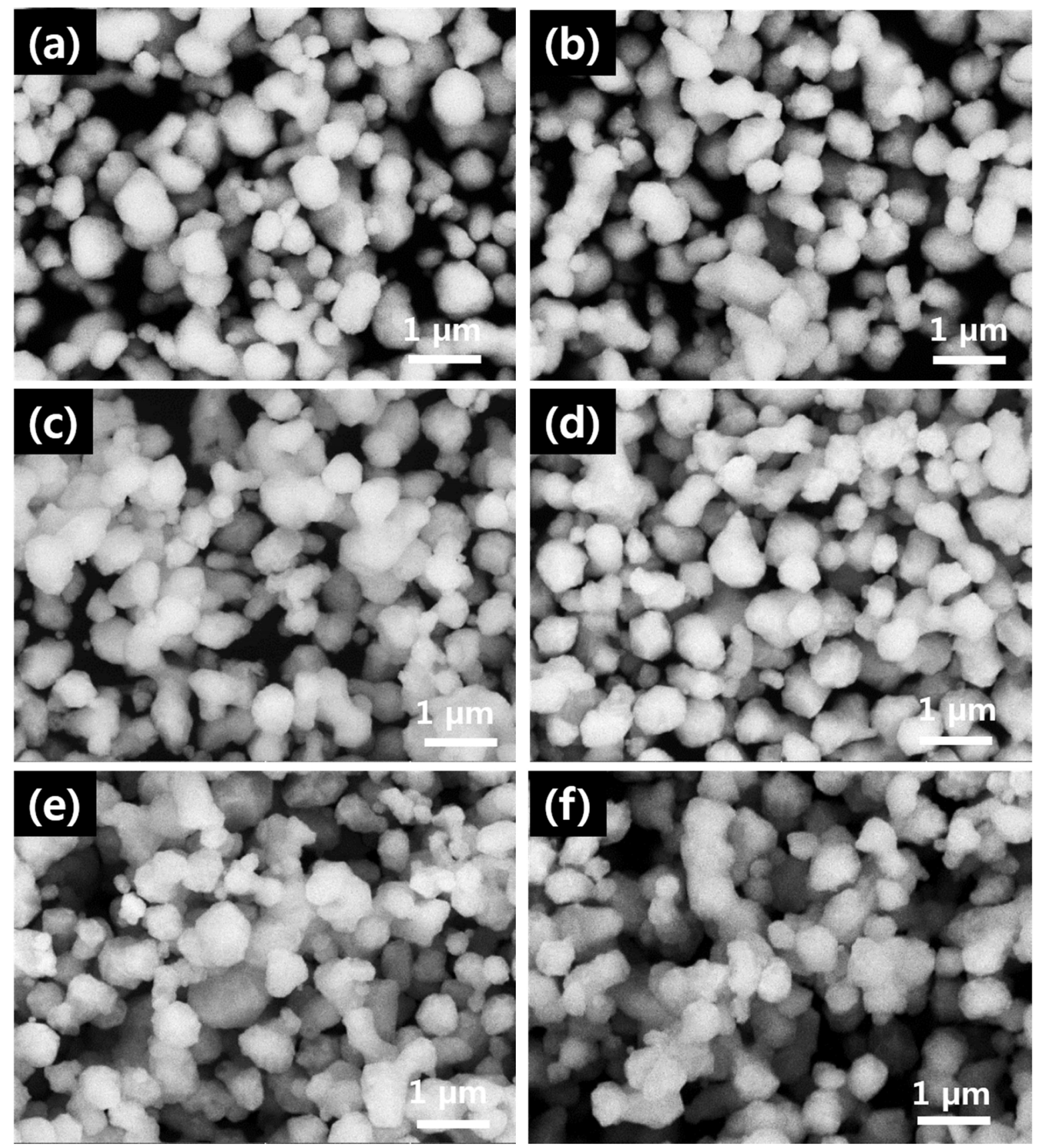

Fig. 2. BSE images of Ag-coated Cu particles fabricated by the multi-step addition of Ag plating solution after the (a) $1^{\text {st }}$, (b) $2^{\text {nd }}$, (c) $3^{\text {rd }}$, (d) $4^{\text {th }}$, and (e) $5^{\text {th }}$ step and after (f) $\mathrm{l} h$ of holding after the $5^{\text {th }}$ step 
4502A-3UES-SN, Termo). To evaluate the antioxidation behavior of Ag-coated $\mathrm{Cu}$ particles, thermogravimetric-differential scanning calorimetry (TG-DSC, Q 600, TA Instruments) was also conducted in the isothermal mode at $150^{\circ} \mathrm{C}$ after heating at a rate of $20^{\circ} \mathrm{C} / \mathrm{min}$.

\section{Results and discussion}

Figure 1 shows SEM images of submicroscale $\mathrm{Cu}$ particles fabricated in-house via a wet process. The $\mathrm{Cu}$ particles had slightly irregular shape, and the average size was $705 \mathrm{~nm}$ (standard deviation: $177 \mathrm{~nm}$ ).

Figure 2 presents the BSE images of Ag-coated Cu particles fabricated in ethylene glycol without any additives by the five-step addition of a Ag plating solution (3 wt\% content). Discrete Ag particles less than $100 \mathrm{~nm}$ and thin Ag coatings on the $\mathrm{Cu}$ particles formed during the early addition steps. As the number of Ag plating steps increased, the thickness of $\mathrm{Ag}$ coatings increased, and small Ag particles agglomerated into Ag coatings. Finally, Ag-coated Cu particles aggregated. Moreover, the aggregation became more severe during the 1-h hold after the $5^{\text {th }}$ addition step.

Figure 3 shows BSE images of Ag-coated Cu particles fabricated without any additives by the eight-step addition of a $\mathrm{Ag}$ plating solution (3 wt\% content). Similar to the results above, small, discrete Ag particles and thin Ag coatings formed during the early steps. As the number of Ag coating steps increased, the Ag coating thickness increased, and small Ag particles agglomerated into Ag coatings. Eventually, the aggregation between Ag-coated $\mathrm{Cu}$ particles became severe. Given the aggregation of particles and the incorporation of fine Ag particles into the Ag-coated $\mathrm{Cu}$ particles, the final morphology of the Ag-coated $\mathrm{Cu}$ particles was very rough. In particular, particles with dents were observed after the fifth addition step, and the number of particles increased with the number of addition steps. This phenomenon can be attributed to the strong galvanic displacement reaction. When a complete Ag coating is formed on a specific region of the $\mathrm{Cu}$ surface, the additional galvanic displacement between $\mathrm{Cu}$ atoms and $\mathrm{Ag}$ ions can proceed more quickly on other regions that are still exposed to the solution. The areas of Cu exposed to the solution decrease during Ag plating, but region that is not coated with Ag gradually transforms into a dent due to the continuous dissolution of $\mathrm{Cu}$ atoms. Hence, the number of particles with a significant dent increases with an increase in the Ag coating thickness or in the number of Ag plating steps. In summary, although the size distributions of particles in Figs. 1 and 2 were wide, it was evident that the average particle size increased slightly with an increase in the number of Ag plating steps. The results are attributed to the aggregation between particles and the increase in the Ag coating thickness.

Figure 4 shows the EDS results for Ag-coated Cu particle samples prepared by the multi-step addition of a Ag plating solution. Figure 4a presents the amount of Ag measured during the
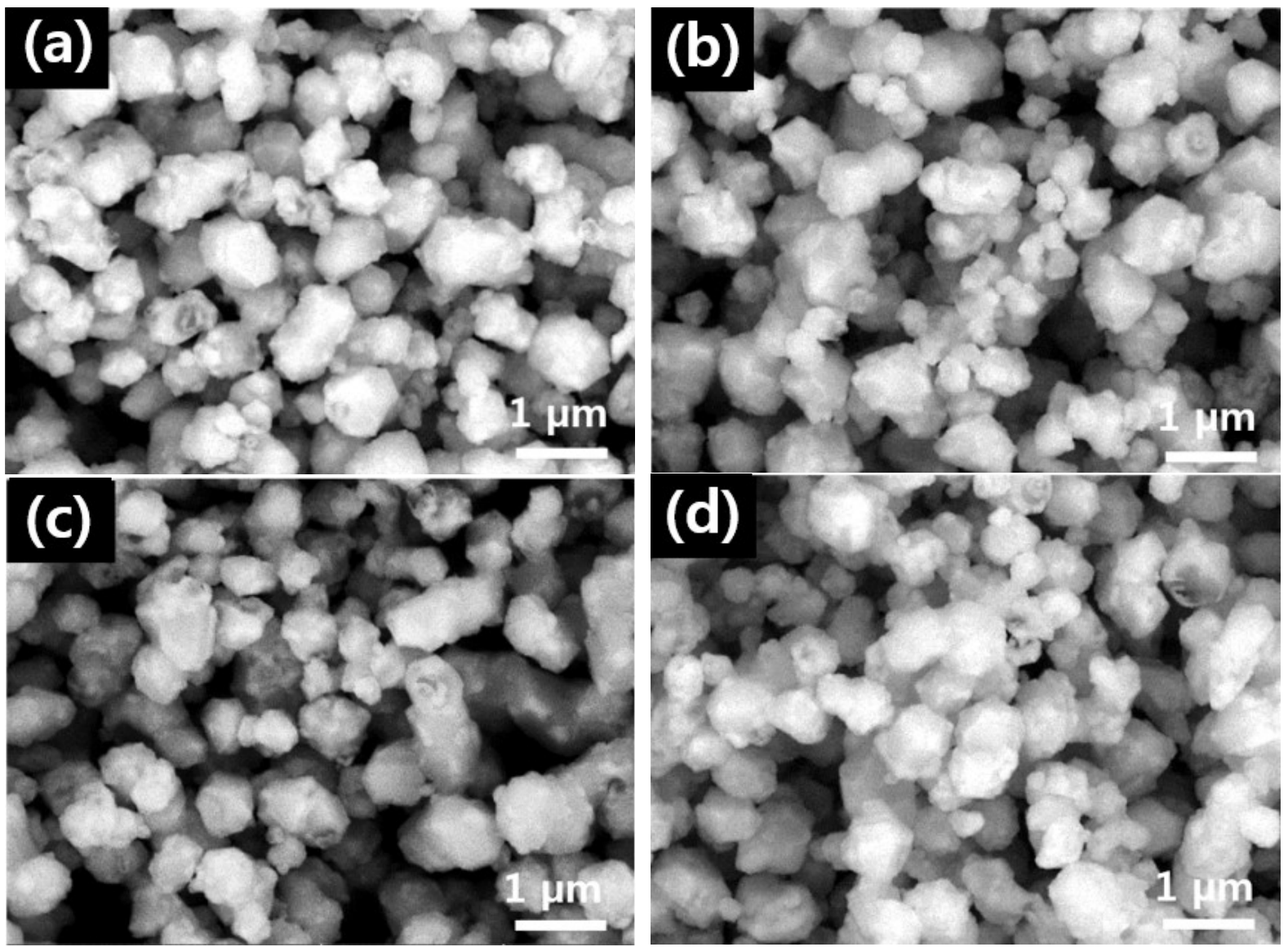

Fig. 3. BSE images of Ag-coated Cu particles fabricated by eight-step addition of Ag plating solution after the (a) $5^{\text {th }}$, (b) $6^{\text {th }}$, (c) $7^{\text {th }}$, and (d) $8^{\text {th }}$ step 
five-step plating process using $3 \mathrm{wt} \%$ Ag solution. As the number of steps increased, the amount of Ag increased and eventually reached $14.77 \mathrm{wt} \%$, which is close to the intended final content of $15 \mathrm{wt} \%$. Figure $4 \mathrm{~b}$ shows the amount of Ag measured during the eight-step plating using 3 wt\% Ag solution. Similarly, the Ag content increased with the number of plating steps. However, the Ag content was nearly saturated after the $7^{\text {th }}$ step, and the final amount of Ag was $21.14 \mathrm{wt} \%$, which was far lower than the intended final content (25 wt\%). This result indicates that the added Ag ions were not fully reduced to the Ag shells and that the degree of reduction decreased abruptly from a high Ag content level. The Ag coating process in this study proceeded only by a pure galvanic displacement reaction without any reductants. Therefore, more complete Ag coatings produced via an increase in the area of Ag coatings would block the galvanic displacement reaction between $\mathrm{Cu}$ atoms and $\mathrm{Ag}$ ions.
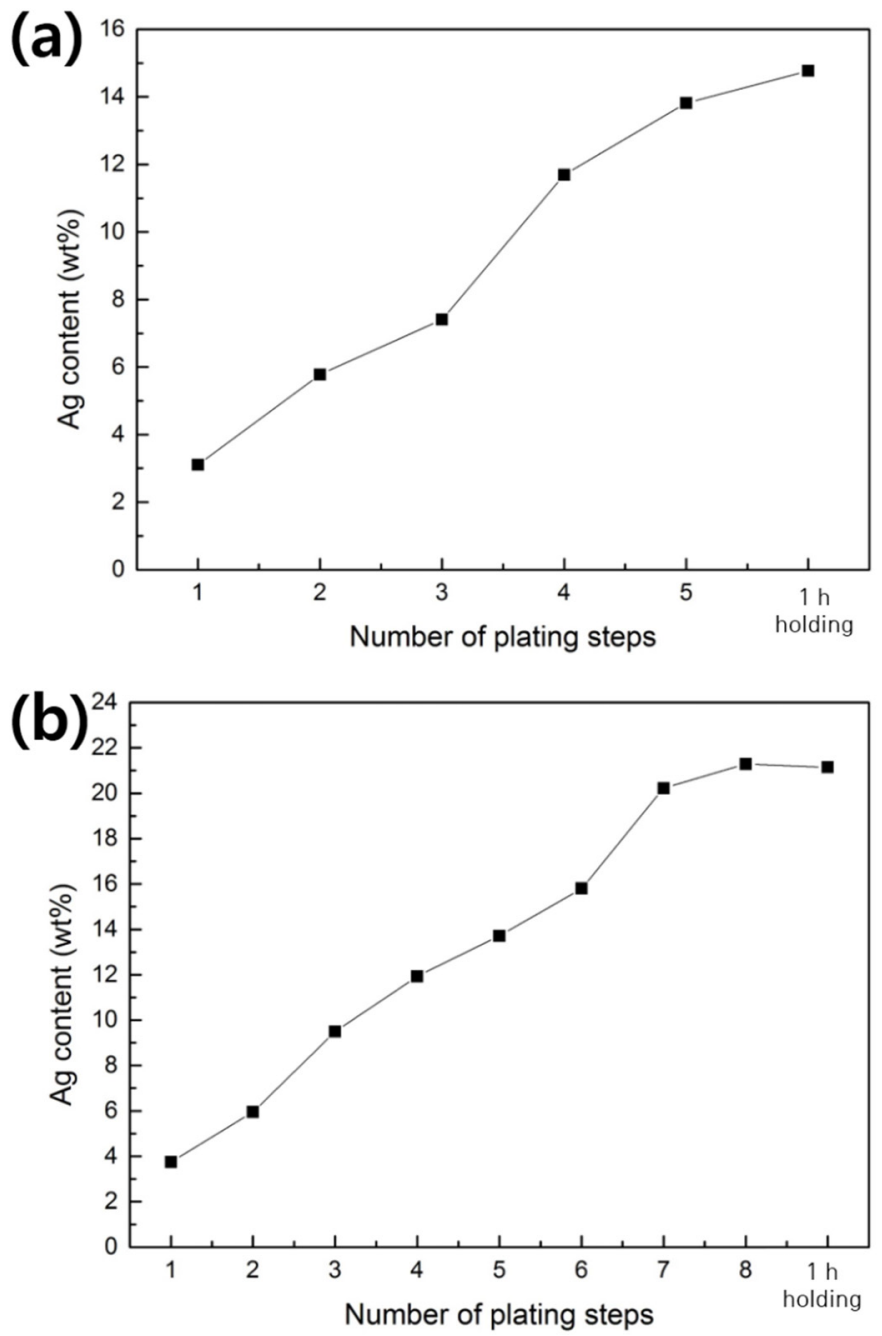

Fig. 4. EDS results measured as a function of the number of addition steps for Ag-coated Cu particles prepared by the multi-step addition of Ag plating solution: (a) five-step and (b) eight-step plating

Figure 5a shows the estimated and measured average particle sizes as a function of the number of Ag plating steps for Ag-coated $\mathrm{Cu}$ particles fabricated by the five-step addition of the Ag plating solution. When the size of the spherical Cu core particles was $705 \mathrm{~nm}$, it was estimated that the size of the Agcoated $\mathrm{Cu}$ particles increased from $711 \mathrm{~nm}$ to $734 \mathrm{~nm}$ between the first and the fifth addition steps. Given that the actual shapes of the $\mathrm{Cu}$ core particles were not spherical but were polygonal, the resultant average size of the Ag-coated $\mathrm{Cu}$ particles after the first addition step was slightly higher because the average thickness of the Ag shells increased according to the decrease in the surface area. However, the measured size showed a striking discrepancy, and the degree of the discrepancy accelerated after the third (9-wt\% Ag-coating condition) and fourth (12-wt\% Ag-coating condition) additions, indicating that the average size of the final Ag-coated $\mathrm{Cu}$ particles reached $851 \mathrm{~nm}$. This discrepancy is attributed to the agglomeration between fabricated Ag-coated Cu particles as observed in Fig. 2. Figure 5a shows that the agglomeration occurred immediately after the first addition and accelerated during subsequent plating steps. It finally slowed at the fifth step. Figure $5 b$ presents the average thickness of the Ag coatings estimated as a function of the number of Ag plating steps with respect to the size of Cu core particles. As in the calculation in Fig. 5a, the Cu core particles were assumed to
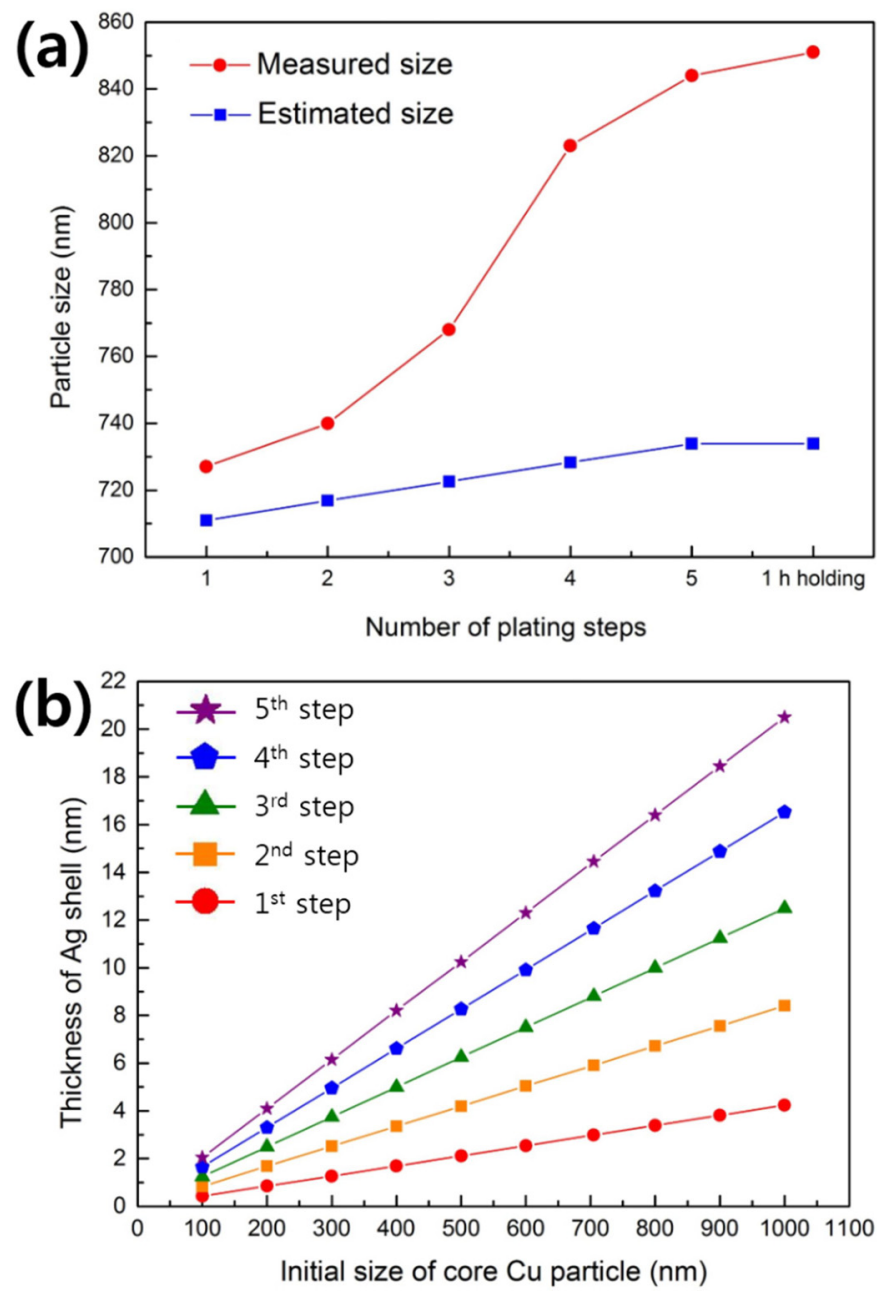

Fig. 5. (a) Estimated and measured average particle sizes as a function of the number of Ag plating steps for Ag-coated $\mathrm{Cu}$ particles fabricated by the five-step addition of Ag plating solution and (b) the average thickness of the Ag coating estimated as a function of the number of Ag plating steps with respect to the size of $\mathrm{Cu}$ core particles 
be spheres with perfectly uniform Ag coatings. When the size of the $\mathrm{Cu}$ core particles is $705 \mathrm{~nm}$, the average thicknesses of the Ag shell calculated after the first five additions are 3.0, 5.9, 8.8, 11.7, and $14.5 \mathrm{~nm}$, respectively. However, given the increase in the average Ag shell thickness with the average size of the core particle, the Ag shell thickness obtained in the actual sample with agglomerated particles was thicker than the calculated results by several nanometers.

Figure 6 shows the TG-DSC results for Ag-coated Cu particles prepared during the five-step addition of the Ag plating solution. Because the general curing of Ag-coated $\mathrm{Cu}$ pastes is performed in air at $150^{\circ} \mathrm{C}$, the measurement was also conducted during isothermal heating in air at $150^{\circ} \mathrm{C}$. The oxidation point of Ag-coated $\mathrm{Cu}$ in this study was defined as the holding time at which a weight gain of $0.1 \%$ of the minimum total weight of the Ag-coated Cu specimen occurs. The specimen prepared with only one addition of the Ag plating solution (Fig. 6a) showed rapid oxidation after 10 min as well as an oxidation point within $1 \mathrm{~min}$ after heating. Meanwhile, the sample two Ag plating steps (Fig. 6b) showed the initiation of oxidation around 9 min. The samples with three and four Ag plating steps (Fig. 6c,d) displayed oxidation points around $13 \mathrm{~min}$. These results suggest that the antioxidation property of Ag-coated $\mathrm{Cu}$ particles is enhanced when the average Ag coating thickness increases with an increase in the number of plating steps. Consequently, the samples with five Ag plating steps or $1 \mathrm{~h}$ of holding after the fifth Ag plating step (Fig. 6e,f) did not present any notable evidence of oxidation according to the TG curves even after $70 \mathrm{~min}$. The mean oxida-
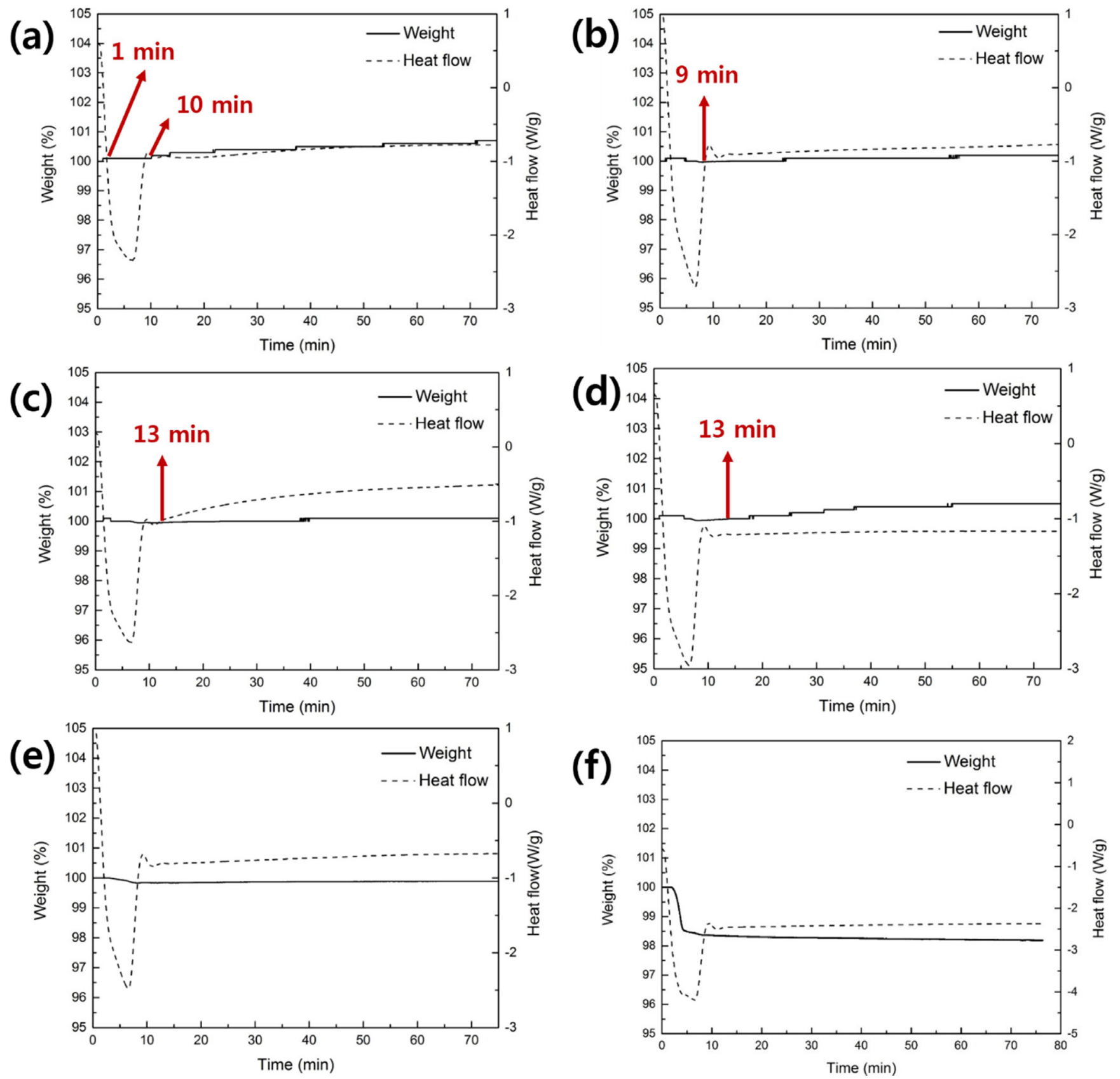

Fig. 6. TG-DSC results of Ag-coated Cu particles for isothermal heating in air at $150^{\circ} \mathrm{C}$ during five-step $\mathrm{Ag}$ plating after the (a) $1^{\text {st }}$, (b) $2^{\text {nd }}$, (c) $3^{\text {rd }}$, (d) $4^{\text {th }}$, and (e) $5^{\text {th }}$ step and (f) after $1 \mathrm{~h}$ of holding after the $5^{\text {th }}$ step 
tion behavior of Ag-coated Cu particles must be considered with statistics and probabilities. The Ag-coated $\mathrm{Cu}$ particles fabricated with inadequate Ag plating were more likely to have exposed $\mathrm{Cu}$ surfaces due to non-uniform Ag coatings. In contrast, the Ag-coated $\mathrm{Cu}$ particles prepared with adequate Ag plating after five steps had only a few small areas with exposed $\mathrm{Cu}$ surfaces due to the nearly perfect Ag coatings, and thus $\mathrm{Cu}$ oxidation did not occur with isothermal heating in air.

Although the sample prepared immediately after the fifth addition of the Ag plating solution showed a weight loss of only $0.2 \%$ within a time period of less than 8 min to reach $150^{\circ} \mathrm{C}$ (Fig. 6e), the sample prepared with five addition steps and $1 \mathrm{~h}$ of holding showed significant weight loss of $1.5 \%$. Hence, it is assumed that the 1-h holding step allowed organic traces be absorbed on the surfaces of the Ag-coated Cu particles, and the organic substance remained on the surface even after drying.

\section{Conclusions}

Ag-coated $\mathrm{Cu}$ particles were successfully fabricated with submicroscale $\mathrm{Cu}$ particles, which were fabricated in-house, through a multi-step addition method using a Ag plating solution. BSE images of Ag-coated $\mathrm{Cu}$ particles fabricated in ethylene glycol without any reductants indicated the formation of discrete Ag particles with less than $100 \mathrm{~nm}$ sizes and thin Ag coatings on the Cu particles during the early addition steps. However, the thickness of the Ag coatings increased, and the small Ag particles agglomerated into Ag coatings as the number of Ag plating steps increased. Nevertheless, the aggregation between Ag-coated $\mathrm{Cu}$ particles was inevitable because of the absence of additives such as surfactants. A comparison between the measured particle size and the calculated size confirmed the notable aggregation between fabricated Ag-coated Cu particles. The TG-DSC results for the agglomerated Ag-coated $\mathrm{Cu}$ particles after the fifth addition of the Ag plating solution showed no weight increase related to the oxidation of the particles even after $70 \mathrm{~min}$ in air at $150^{\circ} \mathrm{C}$.

\section{Acknowledgment}

This work was supported by Nano-Convergence Foundation (www. nanotech2020.org) funded by the Ministry of Science, ICT and Future Planning (MSIP, Korea) \& the Ministry of Trade, Industry and Energy
(MOTIE, Korea) [Project Name: Commercialization of 100Gbps optical receiver and transmitter modules based on nano Ag-coated $\mathrm{Cu}$ paste]. The authors also thank Korean Basic Science Institute (KBSI) Busan center for TG-DSC analysis.

\section{REFERENCES}

[1] C. Yang, C.P. Wong, M.M.F. Yuen, J. Mater. Chem. C 1, 40524069 (2013).

[2] S.K. Kang, S. Purushothaman, J. Electron. Mater. 28, 1314-1318 (1999).

[3] M.J. Yim, K.-S. Moon, K.W. Paik, C.P. Wong, J. Adhes. Sci. Technol. 22, 1593-1630 (2008).

[4] W. Qiao, H. Bao, X. Li, Z. Gu, Int. J. Adhes. Adhes 48, 159-163 (2014)

[5] H.-M. Ren, Y. Guo, S.-Y. Huang, K. Zhang, M.M.F. Yuen, X.-Z. Fu, S. Yu, R. Sun, C.P. Wong, ACS Appl. Mater. Interfaces 7, 13685-13692 (2015)

[6] I. Krupa, V. Cecen, A. Boudenne, J. Prokeš, I. Novák, Mater. Des. 51, 620-628 (2013).

[7] Y.-X. Fu, Z.-X. He, D.-C. Mo, S.-S. Lu, Appl. Therm. Eng. 66, 493-498 (2014).

[8] B.K. Park, D. Kim, S. Jeong, J. Moon, J.S. Kim, Thin Solid Films 515, 7706-7711 (2007).

[9] L. Ye, Z. Lai, J. Liu, IEEE Trans. Electron. Packag. Manuf. 22, 299-302 (1999).

[10] Y. Le, K.-S. Moon, A. Whitman, C.P. Wong, IEEE Trans. Compon. Packag. Technol. 29, 758-763 (2006).

[11] Y.-S. Eom, K.-S. Choi, S.-H. Moon, J.-H. Park, J.-H. Lee, J.-T. Moon, ETRI J. 33, 864-870 (2011).

[12] R. Zhang, W. Lin, K. Lawrence, C. P. Wong, Int. J. Adhes. Adhes. 30, 1673-1697 (2008).

[13] E.B. Choi, J.-H. Lee, J. Alloys Compd. 643, S231-S235 (2015).

[14] J. Zhao, D. Zhang, J. Zhao, J. Solid State Chem. 184, 2339-2344 (2011).

[15] X. Xu, X. Luo, H. Zhuang, W. Li, B. Zhang, Mater. Lett. 57, 3987-3991 (2003).

[16] S.-S. Chee, J.-H. Lee, J. Mater. Chem. C 2, 5372-5381 (2014).

[17] H.T. Hai, J.G. Ahn, D.J Kim, J.R. Lee, H.S. Chung, C.O. Kim, Surf. Coat. Technol. 201, 3788-3792 (2006).

[18] Y.-S. Eom, H.-S. Lee, H.-C. Bae, K.-S. Choi, J.-H. Lee, Proceedings of 2015 European Microelectronics Packaging Conference (EMPC) IEEE Friedrichshafen, 1-5 (2015). 